\title{
Targeted Development of Sustainable Green Catalysts for Oxidation of Alcohols via Tungstate-Decorated Multifunctional Amphiphilic Carbon Quantum Dots
}

Masoumeh Mohammadi, ${ }^{\S}$ Aram Rezaei, ${ }^{*}$ Ardeshir Khazaei, ${ }^{*}{ }^{*}$ Shu Xuwei ${ }^{\phi}$ and Zheng Huajun ${ }^{\phi}$

$\S$ Faculty of Chemistry, Bu-Ali Sina University, Hamedan P. O. Box 38695-65178, Iran

$¥$ Nano Drug Delivery Research Center, Health Technology Institute, Kermanshah University of Medical Sciences, Kermanshah P. O. Box 67145-1673, Iran

$\Phi$ Department of Applied Chemistry, Zhejiang University of Technology, Hangzhou P. O. Box 310032, China

${ }^{*}$ Corresponding authors:

Phone office: +98 8334276489 E. Mail: aram.rezaei@gmail.com, aram.rezaei@kums.ac.ir

Phone office: +98 8118282807 E. Mail: a khazaei@basu.ac.ir

Detailed list of CONTENTS of the supporting information

\begin{tabular}{|c|c|}
\hline List of contents & Page \\
\hline $\begin{array}{c}\text { Title, author's name, } \\
\text { address and table }\end{array}$ & S-1 \\
\hline Figure S 1 & S-2 \\
\hline Table S 1 & S-2 \\
\hline Figure S 2 & S-3 \\
\hline Figure S 3 & S-4 \\
\hline Figure S 4 & S-5 \\
\hline Figure S 5 & S-6 \\
\hline Figure S 6 & S-7 \\
\hline Figure S 7 & S-8 \\
\hline
\end{tabular}




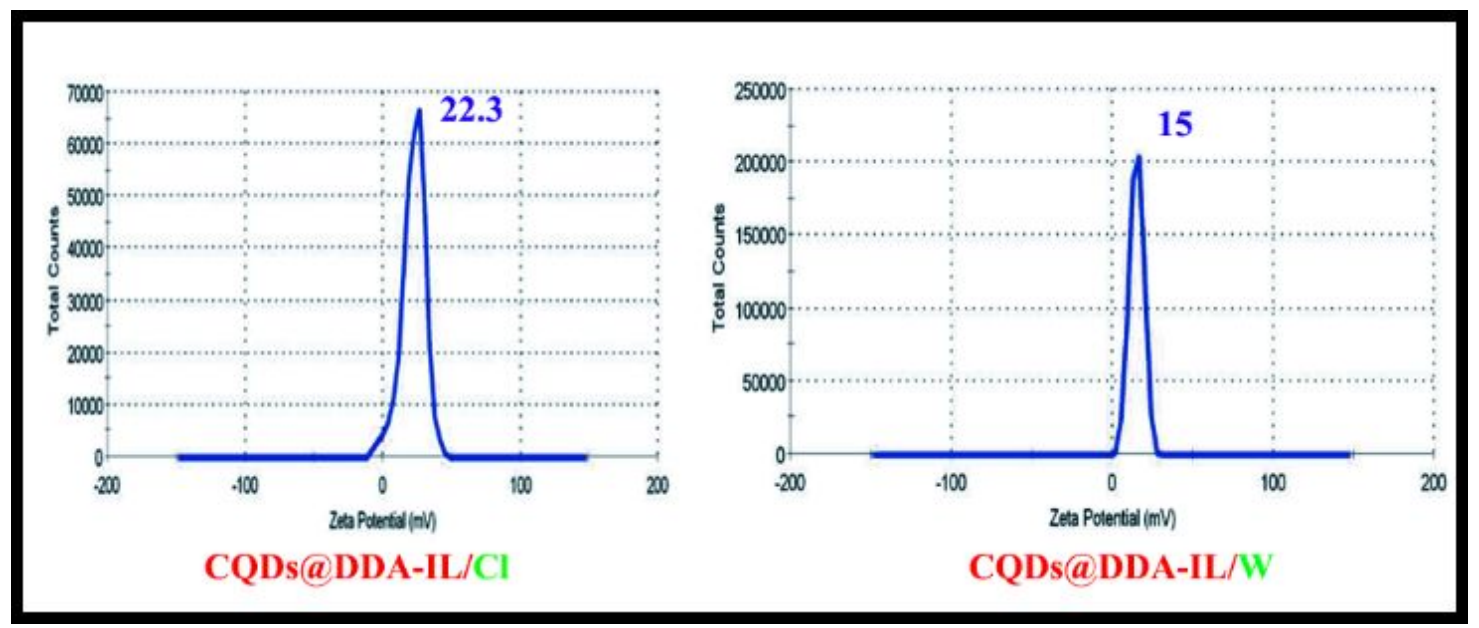

Figure S 1. Zeta potential distribution graph of the CQDs@DDA-IL/Cl and CQDs@DDA-IL/W.

\begin{tabular}{|c|c|c|c|}
\cline { 2 - 4 } \multicolumn{1}{c|}{} & \multicolumn{2}{c|}{$\begin{array}{c}\text { wt \% results } \\
\text { of EDS analysis }\end{array}$} & $\begin{array}{c}\text { wt\% results } \\
\text { of XPS analysis }\end{array}$ \\
\hline Elements & CQDs@DDA-IL/Cl & CQDs@DDA-IL/W & CQDs@DDA-IL/W \\
\hline $\mathbf{C}$ & 49.46 & 44.85 & 63.24 \\
\hline $\mathbf{O}$ & 23.98 & 30.17 & 21 \\
\hline $\mathbf{N}$ & 20.26 & 18.91 & 12.36 \\
\hline $\mathbf{N a}$ & 0.27 & 0.6 & 0.34 \\
\hline $\mathbf{C l}$ & 6.03 & 0.54 & - \\
\hline $\mathbf{W}$ & - & 4.93 & 1.17 \\
\hline $\mathbf{S i}$ & - & - & 1.89 \\
\hline
\end{tabular}

Table S 1. wt\% results of EDS and XPS analyses. 


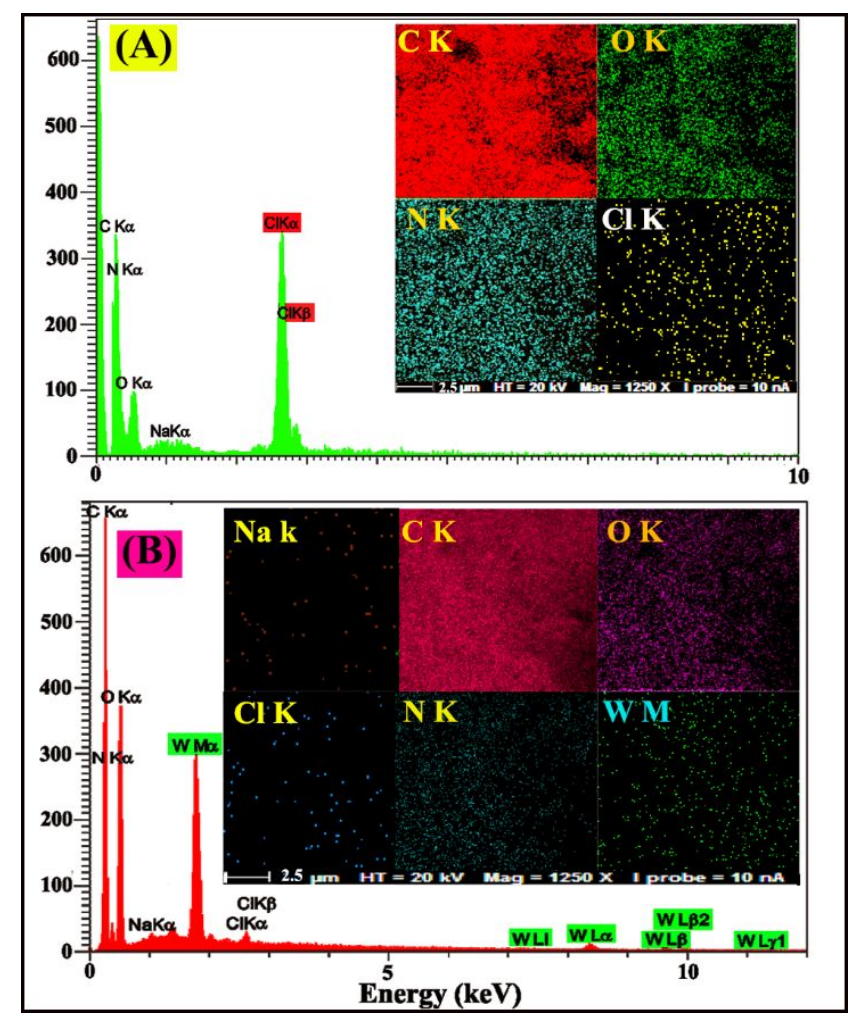

Figure S 2. EDS profile and corresponding elemental mapping images of (A) the CQDs@DDA$\mathrm{IL} / \mathrm{Cl}$ and (B) the CQDs@DDA-IL/W. 


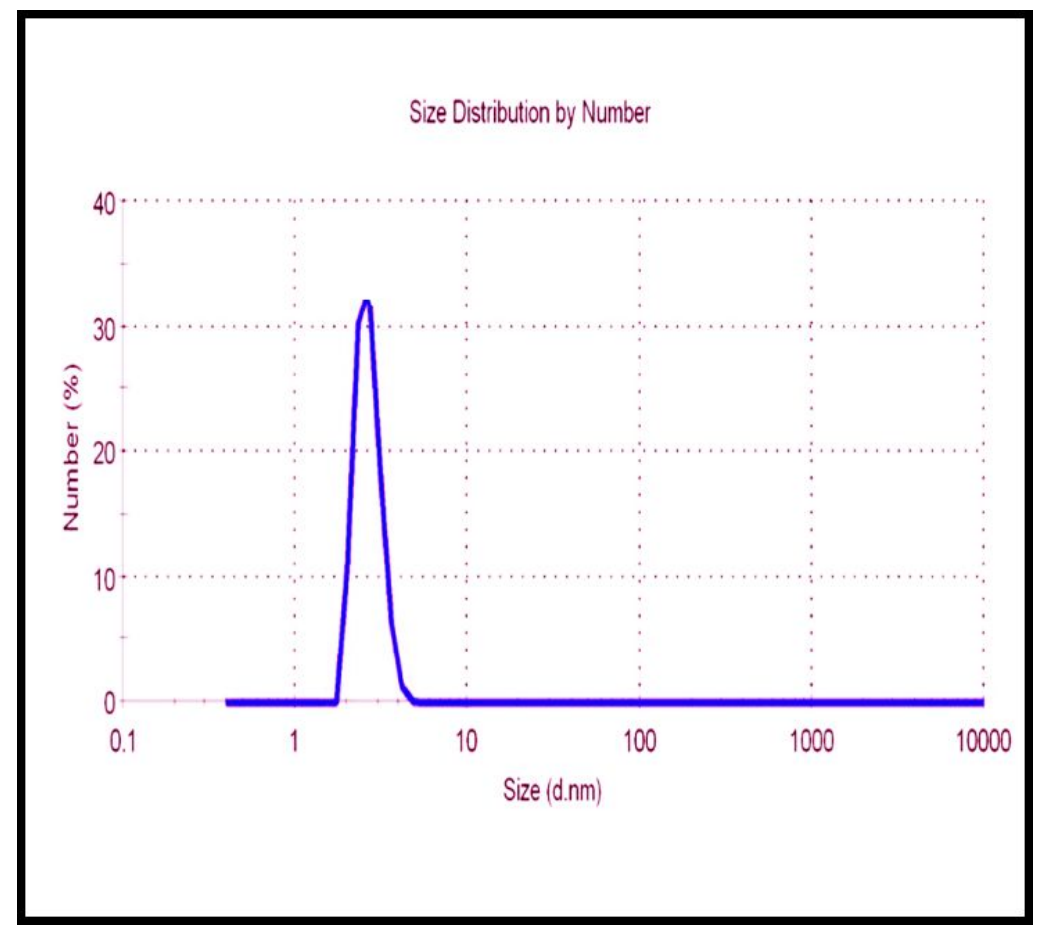

Figure S 3. Size distribution graph of the CQDs@DDA-IL/W aqueous solution. 


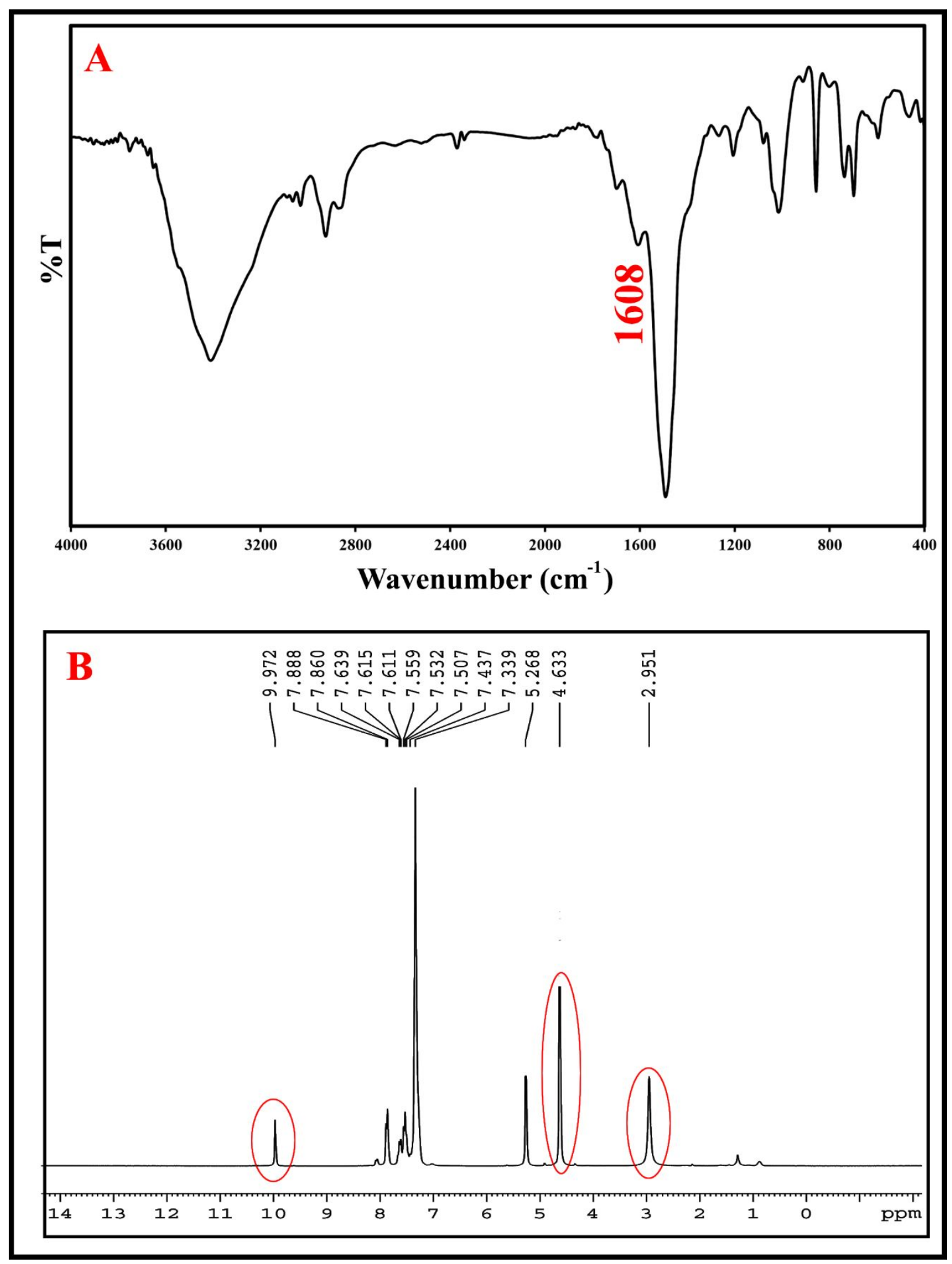

Figure S 4. (A) FT-IR spectrum and (B) ${ }^{1} \mathrm{H}$ NMR spectrum of the extracted reaction mixture of the benzyl alcohol oxidation in the $\mathrm{CDCl}_{3}$. 


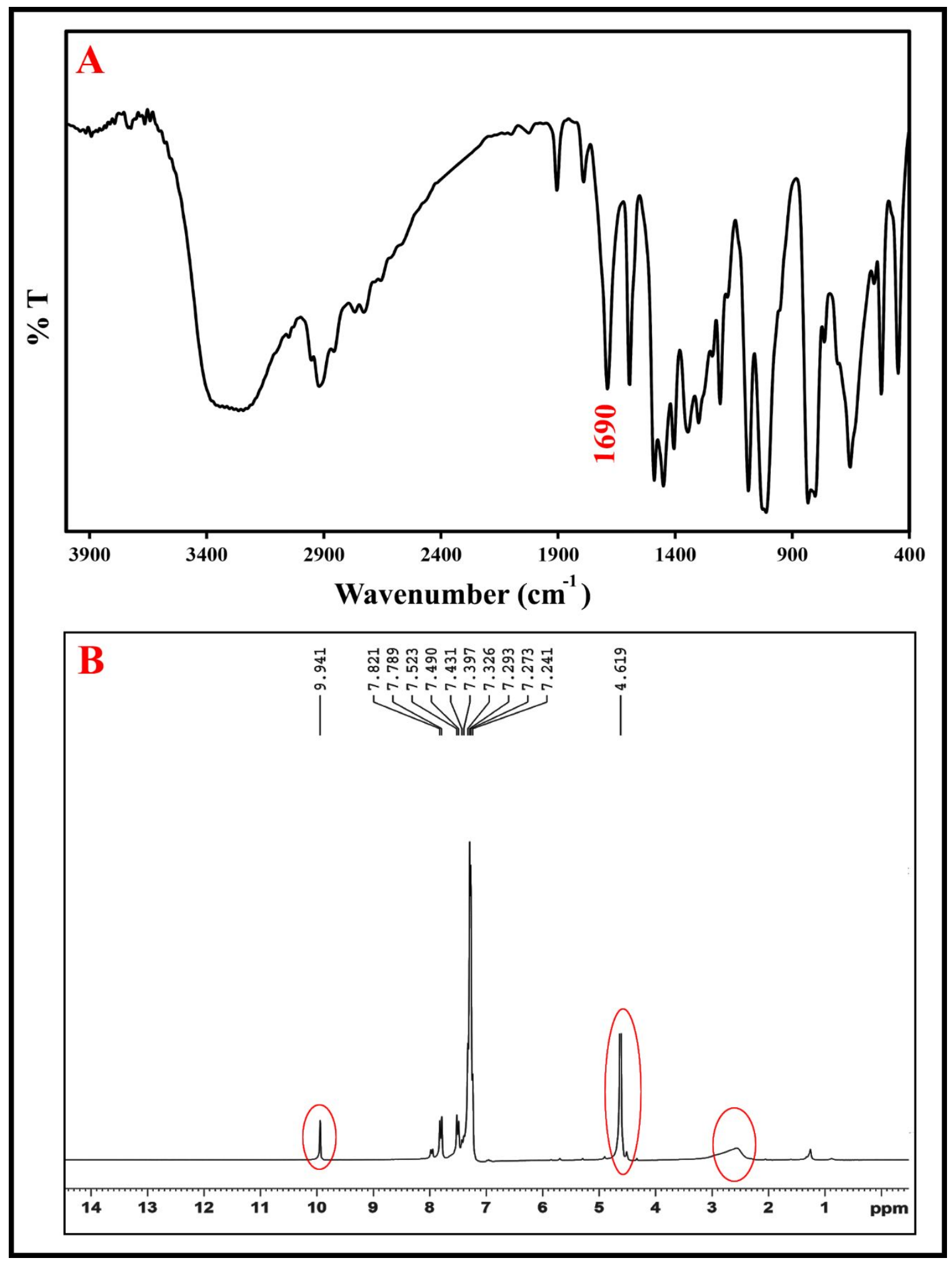

Figure S 5. (A) FT-IR spectrum and (B) ${ }^{1} \mathrm{H}$ NMR spectrum of the extracted reaction mixture of the 4-chlorobenzyl alcohol oxidation in the $\mathrm{CDCl}_{3}$. 


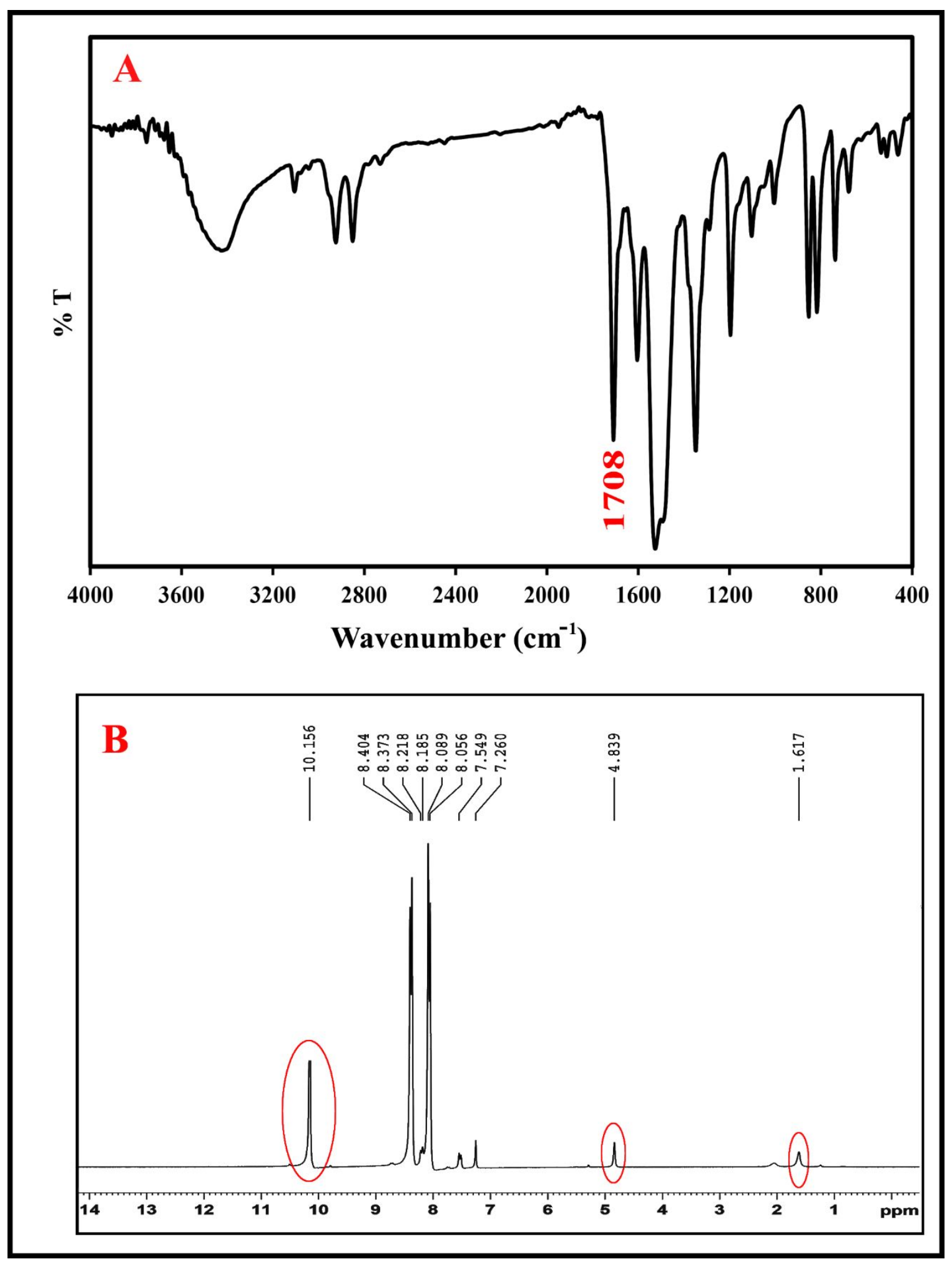

Figure S 6. (A) FT-IR spectrum and (B) ${ }^{1} \mathrm{H}$ NMR spectrum of the extracted reaction mixture of the 4-nitrorobenzyl alcohol oxidation in the $\mathrm{CDCl}_{3}$. 


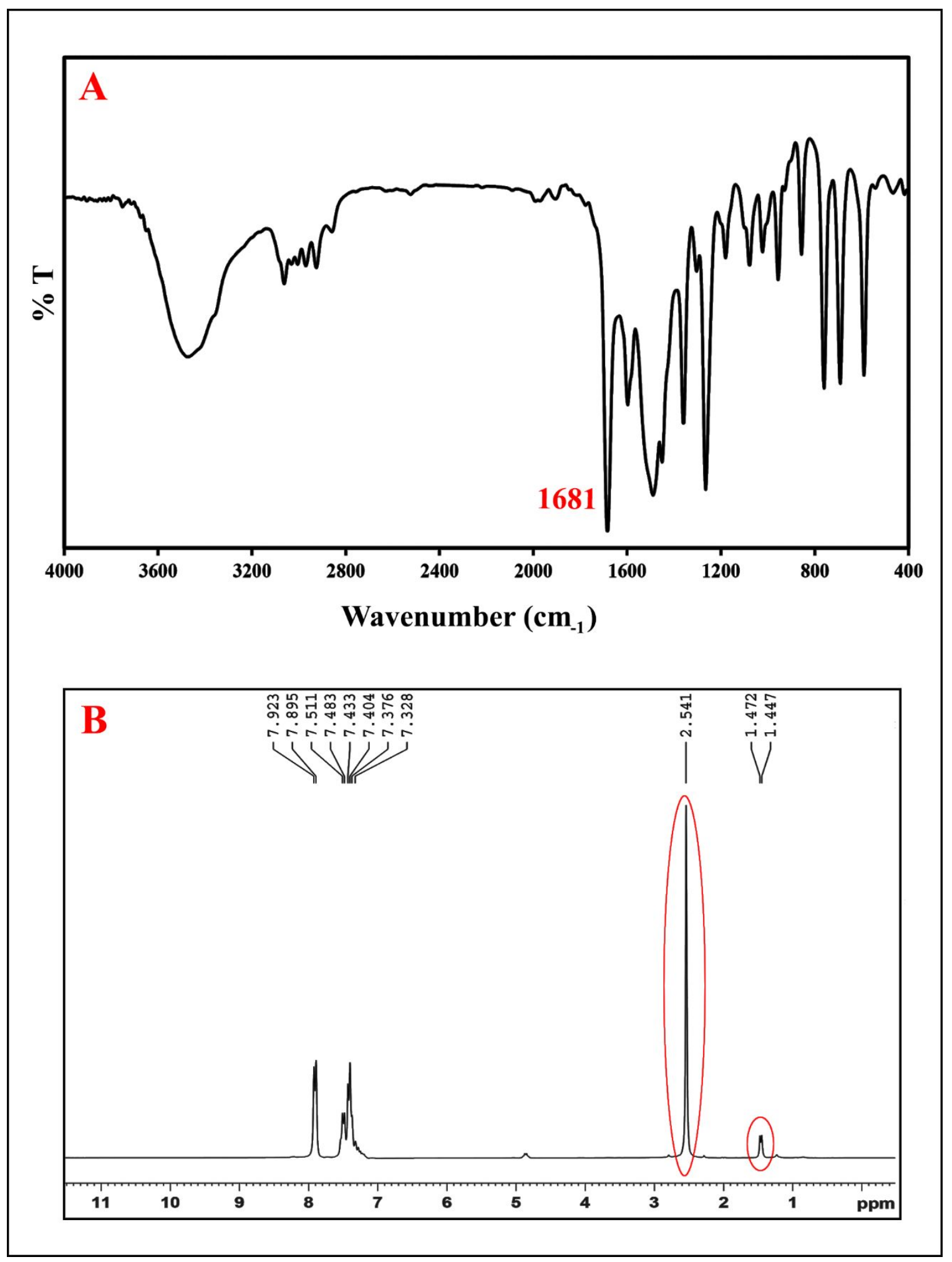

Figure S 7. (A) FT-IR spectrum and (B) ${ }^{1} \mathrm{H}$ NMR spectrum of the extracted reaction mixture of the 1-phenylethanol oxidation in the $\mathrm{CDCl}_{3}$. 